\title{
Conspicuous Generosity
}

\author{
Tore Ellingsen* Magnus Johannesson**
}

September 2010

\begin{abstract}
We develop a simple model of generous behavior. It is based on the premise that some people are generous, but everyone wants to appear generous - especially in the eyes of other generous people. Although non-monetary donations are always inefficient, they frequently occur in equilibrium because they facilitate signaling. The model helps to explain the prevalence of volunteering, the nature of Christmas gifts, and the taboo against paying cash in return for friendly favors. Finally, and perhaps most notably, the model explains why it is so common to ask for non-monetary favors and so uncommon to ask for money.
\end{abstract}

JEL CLASSIFICATION: A13, J20

KEYWORDS: Altruism, non-monetary gifts, volunteering.

*Address: Department of Economics, Stockholm School of Economics, Box 6501, S-113 83 Stockholm, Sweden. Email: gte@hhs.se.

**Address: Department of Economics, Stockholm School of Economics, Box 6501, S-113 83 Stockholm, Sweden. Email: hemj@hhs.se.

We are grateful to the Torsten and Ragnar Söderberg Foundation (Ellingsen) and the Swedish Research Council (Johannesson) for financial support. Earlier versions of this paper were circulated under the title "Generosity". Thanks to Jim Andreoni, Tomas Broberg, Mike Burkart, Simon Gächter, Andrew Postlewaite, Lisa Román, Paul Segerstrom, Jean-Robert Tyran, Robert Östling, several anonymous referees, and seminar participants at CERGE-EI, ECARES, Copenhagen University, Stockholm School of Economics, Stockholm University (IIES), and University of Zürich for their generous comments. Errors are ours. 


\section{Introduction}

A man has two reasons for the things that he does. The first one is pride and the second one is love.

Hüsker Dü ${ }^{1}$

Why is it sometimes acceptable to ask colleagues, friends and neighbors to move one's furniture, getting amateur service from people who never contemplated entering the moving business, but unacceptable to ask the very same people to sponsor a professional mover? And why do people volunteer for charitable causes even when it would generate larger benefits for the recipients if the donor spent the hours at work and donated the wage? Conventional economic thinking suggests that these practices are plainly inefficient and should not exist.

Non-monetary gifts appear similarly inefficient. Givers sometimes buy suboptimal presents, and according to Waldfogel $(1993,2002)$ the resulting average deadweight loss of Christmas gifts is about ten percent of the purchase price. In addition, donors spend valuable time and effort in order to find an optimal present. ${ }^{2}$

Like Mauss (1925) and Titmuss (1971) we believe that volunteering, help, and gifts are due to values and norms that encourage donations of time and effort, but not necessarily of money. ${ }^{3}$ Like them we also suggest that the main reason for nonmonetary generosity is that people wish to appear generous in the eyes of the recipient or other observers. Conversely, recipients care not only about the gifts they obtain, but also about what the donor thinks about their character. That is, both donors and recipients are concerned about social esteem. ${ }^{4}$ This is not to say that an occasion for giving confers a benefit to the donor: Giving is as much about avoiding esteem loss as about making esteem gains.

Although a non-monetary gift is less valuable to the recipient, we show that it may nonetheless be a cost-effective way for the donor to signal altruism and attain the associated esteem. The "cheap signaling" argument runs as follows. If it is valuable for the

\footnotetext{
${ }^{1}$ From the song She Floated Away on the album Warehouse: Songs and Stories (1987). Besides accurately articulating the paper's key assumption, the caption alludes to Camerer (1988, page S194).

${ }^{2}$ Solnick and Hemenway (1996) and List and Shogren (1998) find that recipients often attach a material value to gifts that exceed the gifts' cost, hence questioning the notion that non-monetary gifts are inferior from the recipient's perspective. Waldfogel (1998) argues that the anomaly might be due to the difference between people's willingness to accept (WTA) and their willingness to pay (WTP). To the extent that WTA is greater than WTP because recipients are afraid to offend the donor, as suggested by Plott and Zeiler (2007, p.1454), the non-monetary gift is still inefficient. Indeed, in this case the recipient might afterwards wish not to have received the inalienable gift at all.

${ }^{3}$ Becker (1974) has similarly noted that much generosity is displayed because people care about esteem.

${ }^{4}$ We have chosen to use the word "esteem" because it has been carefully defined by Brennan and Pettit (2004). However, words like approval, prestige, and respect have almost exactly the same meaning.
} 
altruist to be recognized as such, donations may serve as signals and will be distorted upwards relative to the full information benchmark. A reduction in this distortion would be valuable to the donor. We assume, realistically, that altruistic donors have a comparative advantage in making non-monetary donations. For example, although most people may find it onerous to help out with moving, it is usually less onerous to spend such time with a person one feels altruistic towards than with other persons. Hence, the non-monetary donation necessary to distinguish oneself as an altruist is smaller than the corresponding monetary donation. Likewise, even if all kinds of recipient prefer monetary gifts to non-monetary gifts, the utility loss from a non-monetary gift is smaller for a recipient who is altruistic towards the donor.

While the cheap signaling argument explains why donors prefer to give non-monetary gifts, we show that it does not, by itself, explain why recipients ask for non-monetary gifts when they could have asked for money instead. As recipients, we usually prefer efficient gifts. Thus, there is a helping puzzle.

As a resolution to the helping puzzle, we posit that people refrain from requesting money because the value of social esteem depends on who provides it. In particular, we assume that it is more valuable to make a generous impression on a person who herself is generous than on an egoist. Our analysis shows that if people have such preferences, it is often self-defeating to ask for money, as the monetary request reveals a selfish inclination and hence reduces the potential donor's desire to impress. Indeed, we show that this force may preclude monetary requests altogether; either everyone asks their friends to help with the move or egoists pay for their own moves while altruists being less averse to spend time with their friends - ask for their friends' time.

We also show that a selfish friend is always unhappy to be asked, as the equilibrium choice is between declining the request and losing esteem and accepting the request without gaining esteem. If the request is sufficiently demanding, an altruistic friend may be happy to have the opportunity to prove their friendship, but there are also circumstances in which the equilibrium request is so demanding that the altruistic friend would rather not have been confronted with it.

Because we assume that personal help is less efficient than cash transfers, it follows that recipients do not want to pay money for being helped; they merely pay respect. More importantly, altruistic friends have no interest in being offered money for their help, since the benefit of the monetary payment would be outweighed by the need to provide more help in order to credibly signal their altruism. Thus, the model explains why recipients are willing to enforce a taboo against monetary payment for non-monetary favors, while there is no taboo against the compensation of monetary costs.

Before presenting our model and additional results, let us briefly review the related literature, starting with the broad ideas and gradually moving towards specific models of non-monetary generosity.

The notion that people seek social esteem has long been accepted by psychologists, 
sociologists, and economists alike. ${ }^{5}$ Even self-esteem is heavily affected by others' opinions. As Veblen (1934, p.30) put it: "the usual basis for self-respect is the respect accorded by one's neighbors".

Likewise, it almost goes without saying that people prefer to be appreciated by those that they themselves appreciate. Again, classical thinkers articulated the idea most eloquently. In the words of Thomas Hobbes (1651, Ch. XI): "Desire of Praise, disposeth to laudable action, such as please them whose judgement they value; for those men whom we contemn, we contemn also the Praises." For similar statements, see Hume (1739, book II, part I, sect. XI) and Smith (1790, part II, sect. III, para. 10); for these quotes as well as a formal model of such preferences, see Ellingsen and Johannesson (2008).

For evidence that desire for social approval is important for charitable giving, see for example Schwartz (1967), Satow (1975), Harbaugh (1998a,b), Andreoni and Petrie (2004), Soetevent (2005), Dana, Cain, and Dawes (2006), Broberg, Ellingsen, and Johannesson (2007), Ariely, Bracha, and Meier (2009), Andreoni and Bernheim (2009), and Lazear, Malmendier, and Weber (2010). ${ }^{6}$ Nelson and Greene (2003) is a booklength discussion of people's desire to signal their goodness and the consequences of this desire for social organization. ${ }^{7}$ Our purpose is to build a reasonably general formal model of such conspicuous generosity and investigate its implications for donor and recipient behavior.

A large psychological literature documents that the mere concept of money seems to drive people towards selfishness. When they are unconsciously being primed with the concept of money, they become less cooperative than when they are being similarly exposed to other neutral primes; see, e.g., Vohs, Mead, and Goode (2006) and Pfeffer and DeVoe (2008). Ellingsen and Johannesson (2009) find that people are more

\footnotetext{
${ }^{5}$ For typical views on approval in anthropology and sociology, see Homans (1961), Bourdieu (1977,1984), Coleman (1990, 129-131), and Wright (1994). Becker (1974) mentions several classical references, as does Offer (1997). Ellingsen and Johannesson (2007) discuss the role that social esteem plays in the workplace. For a comprehensive review of the esteem concept covering all social sciences, see Brennan and Pettit (2004). Adam Smith put it memorably: "What is the end of avarice and ambition, of the pursuit of wealth, of power, and preheminece? Is it to supply the necessities of nature? The wages of the meanest labourer can supply them ... what are the advantages which we propose to gain by that great purpose of life which we call bettering the human condition? To be observed, to be attended to, to be taken notice of with sympathy, complacency and approbation, are all the advantages which we can propose to derive from it." (Smith, 1790, Ch. ii. 1).

${ }^{6}$ A recent field study by Landry et al. (2006) finds that the beauty of female solicitors is strongly positively related to charitable giving. Although the authors do not pursue the question, a plausible explanation in view of the cited literature is that donors care what the solicitor thinks about them, and more so if the solicitor is attractive.

${ }^{7}$ Relatedly, some biologists think that altruistic behavior in animals has evolved for signaling purposes; see for example Zahavi (1995). Bliege Bird and Smith (2005) links anthropological research to the biological theory.
} 
generous when they have the opportunity only to give time than when they have the opportunity only to give money. ${ }^{8}$

The notion that money makes it too easy to fake regard, and that personalized gifts are therefore more credible, has been discussed by Zelitzer (1994), Carrier (1995), and Offer (1997) among others. Robben and Verhallen (1994) report that recipients significantly prefer gifts that are costly in terms of time and effort rather than money. This finding squares well with the regard signaling hypothesis, at least if we think that recipients appreciate learning that the donor is altruistic towards them. Lee, Piliavin, and Call (1999) explicitly compare people's motivation for giving time, money, and blood. Volunteering of time is more strongly affected by others' expectations than are donations of blood and of money.

A recent field experiment by Kube, Maréchal and Puppe (2010) demonstrates that non-monetary gifts by an employer is interpreted as a more credible signal of kind intentions than is a monetary gift of the same size. Despite workers preferring to receive the money, they also reciprocate the non-monetary gift more strongly.

Andreoni's (1989) seminal model of pure and impure altruism is motivated with reference to donors' concerns for status or acclaim, but does not explicitly trace the link between gifts and social rewards. For simplicity, the donor's "warm glow" (impure altruism) is instead linked directly to the size of the own gift. While this parsimonious model is ideally suited for many applications, especially for understanding the level of charitable giving (Andreoni, 2006), it does not immediately explain why people sometimes give in inefficient ways. In particular, the original version of the model does not explain why the warm glow associated with giving a sum of money would be smaller than the warm glow associated with giving the goods that the sum of money could buy.

Signaling models of gift giving have been proposed by Camerer (1988), Glazer and Konrad (1996), Carmichael and MacLeod (1997), Denrell (1998), Prendergast and Stole (2001), Bénabou and Tirole (2006), Ellingsen and Johannesson (2008) and Andreoni and Bernheim (2009). In all of these, gifts are used to credibly communicate information about the donor's type. ${ }^{9}$ These signaling models can be seen as developments of the impure altruism model. They provide a particular microfoundation that imposes additional structure on the relationship between the nature of the gift and the donor's warm glow. Allowing the set of donor types to be large (a continuum), Andreoni and Bernheim (2009) show that the signaling model fits all the general features of available dictator game evidence, including the bunching at 0 and 50:50 as well as the nearby holes in the distribution of behavior. Moreover, they show that the model success-

\footnotetext{
${ }^{8}$ Relatedly, DeVoe and Iyengar (2009) find that people with differential productivity are more likely to consider it fair that money is allocated according to productivity, compared to having non-monetary rewards allocated according to productivity.

${ }^{9}$ In Glazer and Konrad (1996) the donor desires to signal wealth; in the other models, donors seek to signal altruism.
} 
fully predicts what will happen in new tailor-made experiments in which donors have excuses for giving small amounts.

Camerer (1988) and Prendergast and Stole (2001) are most closely related to our work, as both provide reasons for the existence of non-monetary gifts. Camerer's main story is nonetheless quite different from ours. In his model, inefficient gifts are given only because gift giving is bilateral. Gifts with a low user value prevent people from entering relationships in order to collect gifts. In our model, gift giving is unilateral, and non-monetary gifts are chosen despite their inefficiency, because they are harder to mimic by insincere donors.

Like the present paper, Prendergast and Stole (2001) find that non-monetary gifts ought to be more common when the efficiency loss is small and when the donor's altruism is not too large. However, a crucial feature of their model is that altruistic donors have superior knowledge of the recipient's preferences. Therefore, their model is applicable only when the recipient's desires are not too well known. Our model applies even when the recipient's preferences are common knowledge as well as when the recipient's benefits are monetary, thereby better explaining volunteering for charities and non-monetary generosity in the workplace. Admitting monetary benefits for the recipient also distinguishes our work from other theories of non-monetary gifts, including those focusing on donor paternalism (Pollack, 1988), recipient screening (Blackorby and Donaldson, 1988), and donor commitment (Bruce and Waldman, 1991).

The largest innovation compared to previous formal models is that we consider not only the case of unsolicited gifts, but also the more intricate problem of gift solicitation. In particular, we are able to explain why an acquaintance will ask for time, such as help with moving, but will not ask for money towards the same end.

\section{Model}

We consider the interaction between two persons, henceforth called players, on an occasion where it is customary for one of them (the donor, male) to behave generously towards the other (the recipient, female). For example, the recipient is having a birthday or is moving house.

We consider two kinds of occasions. On the first kind of occasion, that we call a Celebration Game, the occasion is known by both players. The recipient makes no requests, and only the donor makes a decision. On the second kind of occasion, that we call a Helping Game, only the recipient is initially aware of the nature of the occasion. Let $p \in(0,1)$ be the commonly known prior probability that there is an occasion for helping. If the occasion arises, the recipient decides whether to make the occasion known to the donor, and also makes a request concerning the nature of the donor's gift. Following such a request, the donor decides whether to comply with the request or to decline and contribute nothing. (If there is no request, we assume that the donor 
cannot reach the recipient with a gift.)

\subsection{Technology}

The donor and recipient are endowed with $\omega_{D}$ and $\omega_{R}$ units of money respectively. They are also each endowed with $\bar{t}$ units of time. Time is divided between working, earning a wage of 1 per unit of time, and a social activity that benefits the recipient but is costly to the donor. The social activity involves a fixed proportion of donor and recipient time input; if the donor contributes time $t$, the recipient has to contribute $\rho t$, with $\rho \geq 0$. In the case of a birthday gift purchase, it is typical to have $\rho=0$; donors often buy the gift without the recipient's participation. In the case of a move, it is typical to have $\rho>0$; asking others to help out usually implies own participation in the moving. ${ }^{10}$

Money buys a single consumption good at a price of 1 per unit. The donor's consumption is therefore

$$
c_{D}=\omega_{D}+\bar{t}-g^{t}-g^{m},
$$

where $g^{t}$ is the time spent on the social activity (the time gift) and $g^{m}$ is the magnitude of the monetary gift. We assume that time gifts are inefficient. One unit of time spent on the social activity generates recipient consumption $\gamma<1$. Monetary gifts are efficient. Thus, the recipient's consumption is

$$
c_{R}=\omega_{R}+\bar{t}+(\gamma-\rho+\gamma \rho) g^{t}+g^{m} .
$$

Christmas and birthday gifts often entail both monetary and non-monetary costs. At one extreme is the pure monetary gift; at the other extreme is the pure time gift (handcrafted from items found in the woods). Inbetween are objects that are for sale, but where the purchase involves substantial planning or search costs. In a fully general model, we would allow the set of available gift objects to vary along the time and money cost dimension, and results would depend on the properties of this set as well as the recipient's preferences over it. For simplicity, we instead consider only two kinds of gifts - purely monetary gifts and purely non-monetary gifts. More precisely, the set of feasible gifts is

$$
G=\left(g^{M}, g^{T}\right) \in\left\{\{0\} \times \mathbb{R}_{+} \cup \mathbb{R}_{+} \times\{0\}\right\} .
$$

That is, the donor chooses exactly one from only two types of gift, but is free to choose any gift size. While this assumption may seem extreme, the analysis generalizes straightforwardly to the case in which there are two types of gifts that differ in their non-monetary cost share. Allowing the donor to give both a time gift and a monetary

\footnotetext{
${ }^{10}$ While we keep the level of own participation exogenous here, below we shall indicate how to endogenize the participation level within the model's framework.
} 
gift also does not substantially alter the analysis. When allowed, two gifts are only rarely optimal, and all major results continue to hold.

A donor's ultimate action is an element of $G$. Let $\mathcal{G}$ denote the set of probability distributions over $G$, i.e., the set of mixed actions. The recipient's set of actions reflects whether the recipient is allowed to make a request or not. In the first case that we consider below, requests are ruled out, so the recipient has no action to take. In the second case, the recipient can make a request, in which case the recipient's set of mixed actions is also (isomorphic to) $\mathcal{G}$. To the extent that a player randomizes, we assume that only the ultimate pure action is observable by the other player (called the opponent hereafter).

\subsection{Types}

Players differ in their concern for the opponent's consumption. For simplicity, we assume that there are only two types, egoists (selfish players) and altruists (unselfish players). Altruists get more utility from the opponent's consumption than do egoists. The set of types is $\Theta=\{A, S\}$. The letters denote Altruistic and Selfish respectively and will index two parameters of the utility function. The parameter $\alpha_{i}$ is a measure of player $i$ 's concern for the opponent's consumption, and the parameter $\beta_{i}$ is a measure of player $i$ 's disutility from engaging in the social activity. The parameters satisfy the inequalities $\alpha_{A}>\alpha_{S}$ and $\beta_{A}<\beta_{S}$. The first inequality defines the difference between altruism and egoism. The second inequality, which is a crucial assumption, states that the altruist has a lower cost of engaging in the social activity than does the egoist. The justification is that an altruist cares about the opponent and hence finds it less painful to spend time thinking about or interacting with him or her. ${ }^{11}$ Types are private information.

\subsection{Beliefs}

Each player is independently drawn from the same distribution of altruists and egoists, and players share the prior that the opponent is an altruist with probability $a^{0} \in[0,1]$. These priors are updated using Bayes' rule as the game progresses. Let $h_{i}$ denote the history of the game (i.e., the observed actions) when it is player $i$ 's turn to move, and let $\bar{h}$ denote the history at the end of the game. Correspondingly, let $a_{i}\left(h_{i}\right)$ (respectively $a_{i}(\bar{h})$ ) denote the probability that player $i$ assigns to the case that player $j$ is an altruist when it is $i$ 's turn to move (respectively at the end of the game).

\footnotetext{
${ }^{11}$ Buying a present for one we truly love, and helping one we truly like can be almost pleasurable. Precisely therefore, these activities are fine signals. As Camerer (1988, p.S195) points out: "Any net cost of time, energy, or imagination is part of the signaling cost of a gift: the thought does count."
} 


\subsection{Preferences}

Players care about four items: (i) their own consumption; (ii) the opponent's consumption; (iii) the social activity; (iv) social esteem or pride.

To make the analysis of the third item interesting, we will assume that the social activity is relatively unpleasant - avoiding the uninteresting case in which time gifts are preferred because they are efficient.

To be precise about item (iv), let $E$ be the expectations operator, let

$$
\alpha_{i j}=E\left[\alpha_{j} \mid \bar{h}\right]
$$

denote player $i$ 's (ultimate) belief about (or esteem for) player $j$, and let

$$
\hat{\alpha}_{j i}=E\left[\alpha_{j i}\right]
$$

denote player $i$ 's pride. That is, player $i$ 's pride is given by the esteem that player $i$ believes that player $j$ accords to her.

For simplicity, we assume that preferences are additively separable in the four components. Specifically, player $i$ 's utility function can be written as follows:

$$
u_{i}=v\left(c_{i}\right)+\alpha_{i} z\left(c_{j}\right)-\beta_{i} f_{I}\left(g^{t}\right)+p\left(\hat{\alpha}_{j i}\right),
$$

where $I \in\{D, R\}$ indicates whether the player is a donor or a receiver. All functions are continuous and differentiable. We assume that $v$ and $z$ are increasing and concave, and satisfy the boundary conditions $\lim _{c_{D} \rightarrow 0} v^{\prime}\left(c_{D}\right)=\infty$ and $\lim _{c_{R} \rightarrow \infty} z^{\prime}\left(c_{R}\right)=0$. We assume that $f_{I}$ and $p$ are increasing. For simplicity, we finally make the normalizations $f_{I}(0)=0$, and $p\left(\alpha_{S}\right)=0$.

Note that altruism is defined over the opponent's consumption only, neglecting the opponent's disutility from the social activity or the opponent's utility of pride. ${ }^{12}$ Our current formulation (1) also implies that players do not care directly about the opponent's type. Natural generalizations are to let players feel more altruistic towards an altruistic opponent, as in Levine (1998), or to let them care more strongly about an altruistic opponent's beliefs, as in Ellingsen and Johannesson (2008). Since many phenomena can be explained using (1), we stick with this formulation for most of the paper. However, as we demonstrate in Section 4.2, concern about the opponent's type provides the key to our explanation of the house move example.

We refer to $v\left(c_{D}\right)$ as the player's consumption utility, to $\alpha_{i} z\left(c_{R}\right)$ as the player's compassion utility, and to $-\beta_{i} f_{I}\left(g^{t}\right)$ as the player's intimacy disutility. Together, we say that these three terms comprise the direct effect of actions on utility, whereas the social esteem comprises an indirect effect.

\footnotetext{
${ }^{12}$ This assumption is made for analytical convenience and suppresses some potentially interesting issues.
} 
In order to focus attention on the central issues, we consider the case in which altruism is so modest that

$$
v^{\prime}\left(\omega_{D}+\bar{t}\right)-\alpha_{A} z^{\prime}\left(\omega_{R}+\bar{t}\right)>0 .
$$

Under this restriction, keeping in mind the concavity of $v$ and $z$, no donor would give anything were it not for the pride.

\subsection{Strategies and solution concepts}

In the Celebration Game, only the donor moves, and the donor's strategy is a mapping $\sigma_{D}^{C G}: \Theta \rightarrow \mathcal{G}$

In the Helping Game, the recipient first observes whether there is a valid occasion for asking help. ${ }^{13}$ Let $N=\{0,1\}$ denote the two states of nature, with 1 (0) indicating that the occasion is valid (invalid). The two player share the prior that $N=1$ occurs with probability $\eta$. After learning $N$, the recipient decides whether or not to make a request from the set of feasible requests $G$ or to remain silent. Thus, the recipient's strategies are mappings $\sigma_{R}^{H G}: \Theta \times N \rightarrow \mathcal{G} \cup \emptyset$, where $\emptyset$ indicates silence. Donor strategies are mappings $\sigma_{D}^{H G}: \Theta \times\{G \cup \emptyset\} \rightarrow\left\{(0,0), g_{R}\right\}$, where $(0,0)$ indicates that the recipient gives neither money nor time and $g_{R} \in G$ denotes the recipient's actual request. As indicated above, we assume that no gift can be given in case of no request, so $\sigma_{D}^{H G}(\theta, \emptyset)=(0,0)$.

In the Celebration Game, the recipient may update her beliefs about the donor's type, whereas the donor cannot learn anything about the recipient's type. In the Helping Game, both players potentially make inferences about the opponent's type. Let $h_{i}$ denote the (possibly empty) history of actions that player $i$ has observed when it is player $i$ 's turn to move, and let $\bar{h}$ denote the whole history of actions that have been observed at the end of the game.

As a solution concept, we employ Perfect Bayesian Equilibrium (PBE) and refinements thereof. PBE requires that beliefs satisfy Bayes' rule on the equilibrium path. For example, in the Helping Game a pair of strategies $\left(\dot{\sigma}_{D}^{H G}, \dot{\sigma}_{R}^{H G}\right)$ together with a pair of beliefs $\left(\dot{a}_{D}, \dot{a}_{R}\right)$ form a PBE if (i) the strategies are best replies to each other given the beliefs the players hold when it is their turn to move, $\left(\dot{a}_{D}\left(h_{D}\right), \dot{a}_{R}\left(h_{R}\right)\right.$, and (ii) if these interim beliefs as well as the ultimate beliefs $\left(\dot{a}_{D}(\bar{h}), \dot{a}_{R}(\bar{h})\right.$ satisfy Bayes' rule following actions in the support of the equilibrium strategies.

Note that player $i$ 's equilibrium esteem for player $j$ can be written

$$
\alpha_{i j}=\dot{a}_{i}(\bar{h}) \alpha_{A}+\left(1-\dot{a}_{i}(\bar{h})\right) \alpha_{S}=\dot{a}_{i}(\bar{h}) \alpha_{A},
$$

where the last equality follows from the assumption $\alpha_{S}=0$.

\footnotetext{
${ }^{13}$ For simplicity, we ignore why some occasions are valid and others are not. This could be endogenized, for example, by letting the recipient's marginal utility vary across states.
} 
The Intuitive Criterion requires in addition that beliefs following an off-equilibrium action that could only possibly benefit one player type (given the equilibrium payoffs) ascribe probability 1 to the event that the action is taken by this player type. For brevity, we refer to such solutions as intuitive equilibria. The criterion D1, applied to our model, says that if the set of opponent beliefs that would justify a certain outof-equilibrium action for one player type is strictly included in the set that would justify the same deviation for the second player type, then the opponent should assign probability 1 to the event that the deviation is made by the second player type. ${ }^{14}$

The refinements are chosen on the basis of their popularity in the literature. Arguably, they tend to put undue emphasis on fully separating equilibria. In Section 3.4, we briefly discuss how some of the results change if instead we were to apply the concept of Undefeated Equilibrium due to Mailath, Okuno-Fujiwara and Postlewaite (1993).

\section{Analysis of the Celebration Game}

Before analyzing the full Celebration Game, it proves useful to analyze the restricted games in which the donor cannot choose the nature of the gift, only its size.

\subsection{Monetary gifts}

Suppose the donor is confined to give a purely monetary gift. With $g^{m} \in \mathbb{R}_{+}$and $g^{t} \equiv 0$, we can write donor utility as

$$
u_{i}^{m}=v\left(\omega_{D}+\bar{t}-g^{m}\right)+\alpha_{i} z\left(\omega_{R}+\bar{t}+g^{m}\right)+p\left(\hat{\alpha}\left(g^{m}\right)\right) .
$$

Without concern for esteem, the donor would set $g^{m}$ to maximize $v\left(\omega_{D}+\bar{t}-g^{m}\right)+$ $\alpha z\left(w_{R}+\bar{t}+g^{m}\right)$. The optimal value of the gift, call it $g_{*}^{m}(\alpha)$, would then be given by the first-order condition

$$
\alpha z^{\prime}\left(\omega_{R}+\bar{t}+g_{*}^{m}(\alpha)\right)-v^{\prime}\left(\omega_{D}+\bar{t}-g_{*}^{m}(\alpha)\right) \leq 0
$$

with equality if $g_{*}^{m}>0$. By assumption (2) and the concavity of the functions $v$ and $z$ it follows that $g_{*}^{m}=0$. Thus, the donor gives nothing unless there is esteem to be had from giving.

Let us now derive the intuitive equilibrium outcome(s). Since the donor's marginal utility of giving is an increasing function of the donor's altruism and the set of feasible gifts is unbounded, it is quite straightforward to show that the model has one and

\footnotetext{
${ }^{14}$ Originally, these concepts were defined for games where signal receivers (and not only senders) take actions, but the difference is immaterial. For a formal statement of D1 in a game where the audience does not take any action, see Andreoni and Bernheim (2009).
} 
only one intuitive equilibrium outcome, and this is the "best separating" or "Riley" outcome. The solution thus has the feature that the altruistic donor type gives a gift just large enough for the selfish donor type to reveal himself by not giving. More formally, the altruist's gift satisfies exactly the upward incentive constraint

$$
v\left(\omega_{D}+\bar{t}\right)+\alpha_{S} z\left(\omega_{R}+\bar{t}\right) \geq v\left(\omega_{D}+\bar{t}-g^{m}\right)+\alpha_{S} z\left(\omega_{R}+\bar{t}+g^{m}\right)+p\left(\alpha_{A}\right) .
$$

Rearranging terms, and utilizing the assumption that $\alpha_{S}=0$, we see that the altruist's gift $\check{g}^{m}$ is given by

$$
v\left(\omega_{D}+\bar{t}\right)-v\left(\omega_{D}+\bar{t}-\check{g}^{m}\right)=p\left(\alpha_{A}\right) .
$$

The left hand side is the reduction of consumption utility brought about by the gift, and the right hand side is the associated increase in pride. In equilibrium, a selfish donor refrains from giving, because any gift below $\check{g}^{m}$ makes the recipient, or other observers, infer that the donor is selfish, and with no gain in esteem the selfish donor never gives.

Lemma 1 If the donor is confined to giving money, the unique intuitive equilibrium outcome has the property that an altruistic donor gives $\check{g}^{m}$ and a selfish donor gives nothing.

Proof: See Appendix.

While the equilibrium gift $\check{g}^{m}$ is positive and thus larger than the altruist would ideally have wanted, the price is worth paying in order to earn esteem - and to avoid esteem loss. (Relative to the original level of esteem, the altruistic donor gains, but were he not to give, he would lose esteem). Since the altruist's opportunity cost of giving is smaller than the egoist's, there always exists a gift $\check{g}^{m}$ that is small enough not to completely dissipate the utility of esteem and large enough to keep the egoist from pretending altruism.

It is often claimed that generous behavior cannot be driven entirely by the esteem motive; see Brennan and Pettit (2004, pages 36-46) for a recent discussion. The argument is that observers only value true generosity, and hence will not appreciate actions that are taken exclusively in order to gain esteem. As Elster (1983, page 66) puts it: "Nothing is so unimpressive as behavior designed to impress." Signaling models such as ours offer a straightforward resolution: Although pure altruism is insufficient to induce generous behavior, the combination of true altruism and quest for esteem can be sufficient - even when the latter prestige motive is perfectly understood by all. The reason is that while the differences in true altruism are too small to generate differential behavior in and of themselves (because altruism is too weak to generate positive donations), the differences in altruism will be apparent once the prestige motive is added. Just as an addition of noise can amplify weak sounds to a level where they can be perceived, the prestige motive can amplify altruism to a level where differences in 
altruism create perceptible differences in behavior. The generous behavior is designed to impress, yet it succeeds in doing so. ${ }^{15}$ - At the same time, Elster is still right in the sense that we would not be impressed by a gift if we inferred that it was from an egoist trying to pose as an altruist, that is, if the gift's sole purpose were to impress.

Our next step is to consider gifts of time instead of money. As a preliminary step, it is useful to define "donation reward" as the net contribution to donor utility from giving a positive gift. Observe that the entire donation reward can here be ascribed to the presence of esteem. Since the altruist would not have given anything absent the desire for esteem, it is also clear that the donation reward must be smaller than $p\left(\alpha_{A}\right)$. To be precise, the equilibrium reward obtained by the altruist under a purely monetary donation is

$$
\begin{aligned}
\pi^{m} & =v\left(\omega_{D}+\bar{t}-\check{g}^{m}\right)+\alpha_{A} z\left(\omega_{R}+\bar{t}+\check{g}^{m}\right)+p\left(\alpha_{A}\right)-v\left(\omega_{D}+\bar{t}\right)-\alpha_{A} z\left(\omega_{R}+\bar{t}\right) \\
& =\alpha_{A}\left[z\left(\omega_{R}+\bar{t}+\check{g}^{m}\right)-z\left(\omega_{R}+\bar{t}\right)\right],
\end{aligned}
$$

where the second equality follows from (5). That is, the altruistic donor attains a reward that is equal to the compassion utility brought about by the gift.

Observation 1 With purely monetary gifts, the altruist's equilibrium donation reward equals the compassion utility associated with the gift $\check{g}^{m}$.

\subsection{Time gifts}

Let us next consider the case in which the donor gives time but not money. The donor's utility function can now be written as

$$
u_{i}^{t}=v\left(\omega_{D}+\bar{t}-g^{t}\right)+\alpha_{i} z\left(\omega_{R}+\bar{t}+\gamma g^{t}\right)-\beta_{i} f\left(g^{t}\right)+p\left(\hat{\alpha}\left(g^{t}\right)\right),
$$

where we suppress the subscript on $f$ to save on notation (only $f_{D}$ is relevant in this subsection). Giving the recipient $\gamma g^{t}$ units of consumption costs the donor $v\left(\omega_{D}+\right.$ $\bar{t})-v\left(\omega_{D}+\bar{t}-g^{t}\right)+\beta_{i} f\left(g^{t}\right)$. The cost is higher than before both because the gift is inefficient $(\gamma<1)$ and because of the effort cost $\beta_{i} f\left(g^{t}\right)$.

Note that the donor would not give a time gift if there were no esteem benefit. This follows from the assumption embodied in (2) and the fact that time gifts come with additional costs and no additional benefits.

As above, the intuitive equilibrium outcome entails a gift by the altruist that precisely satisfies the egoist's incentive constraint

$$
v\left(\omega_{D}+\bar{t}\right)+\alpha_{S} z\left(\omega_{R}+\bar{t}\right) \geq v\left(\omega_{D}+\bar{t}-g^{m}\right)+\alpha_{S} z\left(\omega_{R}+\bar{t}+\gamma g^{t}\right)-\beta_{S} f\left(g^{t}\right)+p\left(\alpha_{A}\right) .
$$

\footnotetext{
${ }^{15} \mathrm{An}$ anonymous referee points out that we are also impressed by acrobats and "a woman in an amazing black dress", whose behavior is definitely chosen to impress. Our approach covers these cases too, as the audience is really impressed by an underlying talent, such as strength or beauty, that the behavior reveals; it is impressed by the attractive woman in the amazing black dress.
} 
The crucial observation here is that the egoist wanting to mimic altruism faces an additional cost, namely the effort cost $\beta_{S} f\left(g^{t}\right)$. Rearranging terms, and using $\alpha_{S}=0$, we find that the altruistic donor gives a gift $\check{g}^{t}$ satisfying

$$
v\left(\omega_{D}+\bar{t}\right)-v\left(\omega_{D}+\bar{t}-\check{g}^{t}\right)=-\beta_{S} f\left(\check{g}^{t}\right)+p\left(\alpha_{A}\right) .
$$

Again, the selfish donor gives nothing in equilibrium.

Lemma 2 If the donor is confined to giving time, the unique Intuitive equilibrium outcome has the property that an altruistic donor gives $\check{g}^{t}$ and a selfish donor gives nothing.

ProOf: Analogous to the proof of Lemma 1.

The level comparison between $\check{g}^{t}$ and $\check{g}^{m}$ is straightforward.

Observation 2 Ceteris paribus, the material opportunity cost of non-monetary gifts, $\check{g}^{t}$, is smaller than that of monetary gifts, $\check{g}^{m}$.

Comparing (6) to (5) we see that the difference has two separate causes. Non-monetary gifts are smaller both because they yield less utility to the recipient $(\gamma<1)$ and because they are more costly to provide $\left(\beta_{S} f\left(\check{g}^{t}\right)>0\right)$. Since the choice of gift will depend on parameters, this observation by itself is not very helpful, however.

The altruist's donation reward from giving a non-monetary gift is

$$
\begin{aligned}
\pi^{t}= & v\left(\omega_{D}+\bar{t}-\check{g}^{t}\right)+\alpha_{A} z\left(\omega_{R}+\bar{t}+\gamma \check{g}^{t}\right)-\beta_{A} f\left(\check{g}^{t}\right)+p\left(\alpha_{A}\right) \\
& -v\left(\omega_{D}+\bar{t}\right)-\alpha_{A} z\left(\omega_{R}+\bar{t}\right) \\
= & \alpha_{A}\left[z\left(\omega_{R}+\bar{t}+\gamma \check{g}^{t}\right)-z\left(\omega_{R}+\bar{t}\right)\right]+\left[\beta_{S}-\beta_{A}\right] f\left(\check{g}^{t}\right),
\end{aligned}
$$

where the second equality follows from (6).

Observation 3 With purely non-monetary gifts, the altruist's equilibrium donation reward equals the sum of the compassion utility differential and the effort cost differential associated with the smallest separating gift.

\subsection{Money or time?}

Having computed the equilibria of the two restricted games, we are ready to analyze the full Celebration Game. Being able to choose the nature of the gift as well as its size, what will the donor do? As before, the Intuitive Criterion selects the best separating equilibrium.

Lemma 3 The donor gives money if $\pi^{m}>\pi^{t}$ and time if $\pi^{t}>\pi^{m}$. 
Proof: See Appendix.

This key result straightforwardly generalizes to the case of two possible gifts, where one gift involves more money and the other involves more time, with the inefficiency per unit of time being the same. We believe that the result may also generalize to the case in which the donor chooses from a larger set of gifts, as long as each gift can be chosen in any quantity; the Intuitive Criterion, or some stronger equilibrium refinement like D1, would tend to select the least costly separating gift. That is, the optimal type of gift is that which from the point of view of an altruistic donor strikes the best balance between efficiency (compassion) and cheap signaling.

All that remains is to investigate how the various parameters of the model affects $\Delta=\pi^{t}-\pi^{m}$, the altruist's advantage from giving non-monetary rather than monetary gifts. The advantage can be written

$$
\left.\Delta=\alpha_{A}\left[z\left(\omega_{R}+\bar{t}+\gamma \check{g}^{t}\right)-z\left(\omega_{R}+\bar{t}+\check{g}^{m}\right)\right]+\left[\beta_{S}\right)-\beta_{A}\right] f\left(\check{g}^{t}\right) .
$$

Depending on the parameters, $\Delta$ can be either positive or negative. If altruism $\alpha_{A}$ is small (large) relative to the cost difference $\beta_{S}-\beta_{A}, \Delta$ is positive (negative) and time (money) gifts are preferred. The efficiency of the time gift also matters.

Proposition 1 In the intuitive equilibrium, the likelihood of non-monetary gifts is non-decreasing in the efficiency parameter $\gamma$.

Proof: See Appendix.

Although the result borders on the trivial, and is closely reminiscent of Prendergast and Stole (2001), we emphasize it for three reasons. First, it stands in stark contrast to the result of Camerer (1988), where the whole point of non-monetary gifts is their inefficiency. Second, the result is general, in the sense that it does not rest on restrictive assumptions concerning functional forms. Third, there is evidence that efficiency does matter for the choice of gift: Waldfogel (2002) reports that cash gifts are more often given by donors who tend to give unwanted gifts.

Next, consider the effect of an increase in the recipient's wealth, $\omega_{R}$.

Proposition 2 There exists a finite level of recipient wealth $\hat{\omega}_{R}$ such that the equilibrium gift is non-monetary for all $\omega_{R}>\hat{\omega}_{R}$.

Proof: See Appendix.

The intuition is that the donor's concern for increasing the recipient's consumption becomes unimportant, relative to acquiring esteem, as the recipient gets sufficiently rich. As the concern for the recipient's consumption diminishes, so does the size of the gift. Accordingly, the donor becomes less concerned about the efficiency of the 
donation, preferring instead to make a non-monetary donation in order to maximize the esteem rent. There is just no point in giving money to a very rich person. ${ }^{16}$

An increase in the donor's wealth does not have a determinate effect on the nature of the gift. On the one hand, the efficiency loss associated with switching from money gifts to time gifts is magnified as the donor gets richer and donates more. On the other hand, as the separating equilibrium gift gets larger, so does the effort cost differential. Depending on functional forms, either the compassion utility differential or the effort cost differential may increase more as the donor gets richer. A similar argument shows that an increase in the donor's valuation of esteem has an ambiguous effect on the nature of the gift.

\subsection{Discussion}

In a recent field experiment, Kube, Maréchal and Puppe (2010) obtain direct evidence for our conclusion that non-monetary gifts can be a convincing yet cheap signal of kind intentions, despite donors having no special information about recipient preferences. Workers individually hired for a particular short-term job were given unanticipated gifts prior to conducting their tasks, some monetary and others non-monetary. The monetary value of the non-monetary gift was known to the subjects and identical to the monetary gift. In a subsequent survey, people from the same subject pool, but who had not participated in the experiment, were asked to evaluate a number of statements. Each of the subjects were confronted with statements concerning only one of the treatments. These evaluations revealed that people prefer receiving the cash gift, yet consider the non-monetary gift to be a more credible signal of kindness.

The field experiment also revealed that the workers' subsequent performance responded only weakly to cash gifts, but responded positively and strongly to the nonmonetary gift. In order to explain this part of the experimental evidence, we have to extend the model both with respect to the recipient's action set and the assumed preferences. Before considering such major extensions (end of next Section), let us outline various minor generalizations.

For simplicity we have focussed throughout on the case in which altruism is so modest that the least altruistic donors give nothing in a separating Celebration Game equilibrium. However, all the important insights remain when altruism is so great that both types of donor give positive amounts. The only difference is that when the least altruistic donors give a positive amount, they always give money; since they do not get the esteem benefit, there is no point for them in making a non-monetary donation. This observation is consistent with Waldfogel's (2002) observation that cash gifts sometimes carry a stigma; the cash gift reveals the donor's relatively low altruism.

\footnotetext{
${ }^{16}$ It is tempting to conclude that the propensity to give non-monetary gifts should be everywhere increasing in $\omega_{R}$. However, such a monotonicity result appears to require additional assumptions regarding the functional forms of $f$ and $r$.
} 
Much social interaction continues over time. In this case, how will gift giving evolve over the relationship? The problem of dynamic signaling is a difficult one in general. However, if we confine attention to least-cost separating equilibria, Kaya (2009) provides a characterization of the admissible temporal patterns. In our model where the utility functions of the two types differ by multiplicative constants, many time patterns are admissible. However, if the utility of the low type as a function of the size of the gift is a concave transformation of the utility of the high type (instead of a linear transformation), then the altruist would give a large gift in the beginning of the relationship and no gifts thereafter. Conversely, if the transformation is convex, the altruist would give a smaller gift each period. We lack intuition concerning the exact relation between the utility functions, but to the extent that such information can be elicited, the model could be tested by comparing instances of recurrent gift giving to instances of once and for all gifts.

Another extension of the model is to allow a continuum of possible levels of altruism. However, there appears to be something wrong with mechanically assuming separating equilibria: In reality, we doubt that the gift size varies continuously so as to signal the donor's altruism exactly. Instead, it seems to us that gifts often come in certain conventional sizes. To capture this phenomenon, the equilibrium would have to be (at least partially) pooling. We shall now turn to a set of arguments suggesting how pooling may come about.

Over the years, social norms concerning gift giving have caused considerable public debate. This is natural; many people are both donors and recipients, and to the extent that gift giving is socially wasteful, society has an incentive to regulate it. For example, Zelitzer (1994, p79) describes how "At the turn of the twentieth century, as their gift exchanges multiplied, Americans, contemplated, debated, and publicly defined gift transfers." One way to interpret social regulation is as coordination of expectations on a particular equilibrium, for example one that maximizes a weighted sum of utilities for donors and recipients. And in this case, the fully separating equilibrium may do quite poorly. For example, all donor types might sometimes be better off in the pooling equilibrium where no gift is given: In our two-type model, this happens when $a^{0}$ is close to 1. See Mailath, Okuno-Fujiwara and Postlewaite (1993) for a belief-based argument in favor of selecting this equilibrium; their solution concept Undefeated Equilibrium picks the outcome that the "high" type prefers. On their side, recipients in our model typically prefer equilibria in which an average gift is always given to equilibria in which the gift is sometimes large and sometimes small. Thus, equilibria with relatively uniform gifts can be desirable for recipients and (many) donors alike. ${ }^{17}$

Recently, Andreoni and Bernheim (2009), in a continuous type model, have shown that pooling on conventional gift sizes arises naturally if people have a preference for

\footnotetext{
${ }^{17}$ We here eschew attempts to characterize formally the equilibria that would be implemented by some social contract, but we conjecture that the problem can be formulated and solved along the lines proposed by Myerson (1985).
} 
adhering to social norms. Intuitively, it is unattractive to give more than prescribed by the norm, because this represents a norm violation. Thus, sufficiently generous (or norm-minded) types give exactly the prescribed gift. Importantly, this behavior has the knock-on effect that nobody will give gifts that fall slightly short of the norm, because a minor increase in giving would then yield a discrete jump in social esteem. Thus, despite there being a continuous distribution of types, there will be a lumpy distribution of behaviors.

When it comes to the nature of the gift, we have shown that donors often favor nonmonetary gifts. By contrast, recipients always favor cash gifts, as cash gifts are both larger and more useful. If both parties know at the outset that the occasion calls for a donation, as for example in the case of a marriage where the guests know that the couple expects gifts, we would expect the balance to be tilted less strongly in favor of nonmonetary gifts than indicated by our donor-focused analysis. We shall not substantiate this conjecture here except to note that formal analysis could employ Myerson's (1985) approach to bilateral negotiations under one-sided asymmetric information.

Finally, a natural extension is to relax the assumption that both parties are aware that there is a gift-giving occasion, and that the donor is able to give. Let us briefly consider three alternative cases.

(i) If there are purely external and commonly known circumstances that preclude giving, the donor will keep his original level of esteem, and hence maintain the level of pride $p\left(a_{0} \alpha_{H}\right)$. Observe that this outcome is always preferable for the egoist. The egoist does not give in equilibrium, but is better off with the pride $p\left(a_{0} \alpha_{H}\right)$ than with $p(0)$. The altruist may be better or worse off, depending on $a_{0}$. If $a_{0}$ is close to $0(1)$, the separating gift gives a large (small) gain in esteem, so the altruist typically prefers to be able (unable) to give.

(ii) If the donor may be unaware of the occasion, and this possibility is commonly understood, the recipient cannot infer from the lack of a gift that the donor is selfish. (However, altruists presumably are less likely to be unaware.) A qualitatively similar version of our results continue to hold, but the separating equilibrium entails smaller sized gifts, as the aware egoists can pool with the unaware altruists. That is, the better known the celebration opportunity is, the larger the gifts.

(iii) If instead it is the recipient who is unaware of the celebratory occasion, the donor can refrain from giving without suffering any esteem damage at all. ${ }^{18}$ In this case, if the recipient's unawareness is commonly known, the altruistic donor will still

\footnotetext{
${ }^{18}$ For experimental evidence on the role of recipient awareness for the magnitude of gifts, see Dana, Cain, and Dawes (2006), Broberg, Ellingsen, and Johannesson (2007), and Lazear, Malmendier, and Weber (2010).
} 
give, but if $a_{0}$ is large the gift may be very small. (Recall that gift sizes are typically independent of $a_{0}$ in the common knowledge case.) This is the single surprise flower on a happy occasion that the recipient had forgotten. On the other hand, if $a_{0}$ is small, the separating gift must still be large: This is the surprising big bunch of flowers that restores a relationship. Again, of course, our model can explain why the gift is flowers rather than cash.

\section{Analyzing the Helping Game}

In the Celebration Game studied above, both players know that there is cause for giving, and the donor has all the initiative. In the Helping Game, only the recipient knows whether there is cause for giving or not, and the recipient thus initiates the social exchange.

If the recipient chooses to reveal that there is an occasion for giving, the recipient also chooses the type of gift $i \in\{m, t\}$ and the size of the gift, $g^{i} \in \mathbb{R}_{+}$. We assume that the donor cannot respond to a request by giving a larger gift than requested, but that the donor can refrain from giving altogether.

As will become clear, the recipient benefits from being able to restrict the donor's options upwards. ${ }^{19}$ By preventing overly large gifts, the recipient can induce pooling equilibria with larger average gifts. On the other hand, the downward restrictions implied by the request do not really matter; it is possible to show that the outcomes are the same if the request is an interval and the recipient is allowed to make gifts anywhere between zero and the request and not only at the ends of the interval.

Let us say that a request is modest if it is granted in equilibrium by both types of donor and immodest otherwise.

To get a grasp on the trade-off facing the recipient, we first analyze the donor's decision in the face of a small request. Let $\bar{g}_{S}^{m}$ be defined by the equation

$$
v\left(\omega_{D}+\bar{t}-\bar{g}_{S}^{m}\right)+p\left(a^{0} \alpha_{A}\right)=v\left(\omega_{D}+\bar{t}\right) .
$$

That is, $\bar{g}_{S}^{m}$ is the largest monetary gift that a selfish donor is willing to give in order not to reveal his selfishness. Analogously, let $\bar{g}_{S}^{t}$ be defined by the equation

$$
v\left(\omega_{D}+\bar{t}-\bar{g}_{S}^{t}\right)-\beta_{S} f_{R}\left(\bar{q}_{S}^{t}\right)+p\left(a^{0} \alpha_{A}\right)=v\left(\omega_{D}+\bar{t}\right) .
$$

Lemma 4 Let recipient beliefs satisfy D1. Then, any monetary request up to $\bar{g}_{S}^{m}$ or any time request up to $\bar{g}_{S}^{t}$ will be granted by both types of donor. That is, they are modest.

\footnotetext{
${ }^{19}$ Unless the request restricts the donor's options, the Helping Game would be a simple extension of the Celebration game. The only difference is that the recipient's decision to inform the donor might reveal some information about the recipient's type.
} 
Proof: See Appendix.

Intuitively, the egoist prefers to pay the cost of helping and getting some average level of pride $p(\bar{\alpha})$ to being exposed as an egoist and getting the level of pride $p\left(\alpha_{S}\right)$.

Faced with an immodest request, the donor's problem is different.

Lemma 5 There is a non-empty set of requests that are granted by the altruistic donor but not by the selfish donor.

The result follows immediately from Lemmas 1 and 2 . In particular, a monetary request slightly above $\check{g}^{m}$, or a non-monetary request slightly above $\check{g}^{t}$ will be granted by the altruist but not by the egoist.

We are now ready to state our first substantive result about the Helping Game.

Proposition 3 (i) Egoistic donors dislike all requests. (ii) Altruistic donors dislike modest requests, but may like some immodest requests, especially if the recipient's expectations are not too optimistic.

To a selfish donor, any request "puts him on the spot." Compared to the case of no request, esteem cannot be gained in equilibrium, since any request that is acceptable to the egoist is also acceptable to the altruist. Effectively, the choice is between complying and maintaining the recipient's prior and not giving and losing esteem.

The altruistic donor also dislikes modest requests. Since they are not associated with gains in esteem, modest requests are nuisances. Obviously, the altruistic donor may also dislike immodest requests. This is the case when it is better to comply with the request and thereby prove that one is a "good friend" than to reject and to be considered a bad friend, and when the recipient had an optimistic prior. Then, the gain in esteem is small compared to the cost of helping. It is perhaps slightly less obvious that the altruist may like an immodest request, but the idea is simple. If the recipient's prior is sufficiently pessimistic, the altruistic donor will be happy about any request slightly exceeding $\check{g}$. When the recipient is pessimistic, such an immodest request provides a valuable opportunity for the donor to "prove himself" and gain esteem. ${ }^{20}$

Let us now deduce the requests that recipients will make in equilibrium. Since the recipient doesn't know the donor's type, some requests may be accommodated with probability $a^{0}$. Since the return to the request is a lottery, the recipient's risk preferences may in principle matter. However, as long as the size of the gift is small relative to the recipient's wealth, we know from Rabin's (2000) calibration theorem that an expected utility maximizer will be effectively risk neutral. Hence, we assume risk neutrality.

\footnotetext{
${ }^{20}$ The formal proof runs as follows. When $a^{0}$ tends to zero, the difference between $p\left(\alpha_{A}\right)$ and $p\left(a^{0} \alpha_{A}+\left(1-a^{0}\right) \alpha_{S}\right)$ tends to $p\left(\alpha_{A}\right)-p\left(\alpha_{S}\right)$, and since the egoist is just indifferent between giving 0 and $\check{g}$, the altruist (who values the recipient's increase in consumption more) must strictly prefer giving $\check{g}$.
} 


\subsection{Recipient's type is known}

Assume to begin with that the recipient is selfish, and that this is known to the donor. When the recipient's type is known, and the recipient has the first move, the situation is essentially a screening problem, but one where the second mover's decision is driven by signaling concerns.

Let $\bar{g}_{A}^{m}$ be the largest monetary request that an altruistic donor will grant in any equilibrium. Formally, $\bar{g}_{A}^{m}$ is given as the solution to the equation

$$
v\left(\omega_{D}+\bar{t}-\bar{g}_{A}^{m}\right)+\alpha_{A} z\left(\omega_{R}+\bar{t}+\bar{g}_{A}^{m}\right)+p\left(\alpha_{A}\right)=v\left(\omega_{D}+\bar{t}\right)+\alpha_{A} z\left(\omega_{R}+\bar{t}\right) .
$$

Relative to the outcome under donor initiative, a selfish recipient always prefers to ask for larger and (weakly) more liquid gifts.

Observation 4 A recipient who is known to be selfish will ask for $\bar{g}_{S}^{m}$ if $\bar{g}_{S}^{m} \geq a^{0} \bar{g}_{A}^{m}$ and for $\bar{g}_{A}^{m}$ otherwise.

That is, a selfish recipient requests either the largest monetary gift that the selfish donor is willing to give or the largest monetary gift that the altruistic donor is willing to give. The choice between the two requests hinges on the belief $a^{0}$.

\subsection{Recipient private information}

Let us now turn to the case of interest, in which the recipient's type is privately known. Let $g_{i}^{*}$ denote the equilibrium request of type $i$. Our first insight is that asking for a large amount of money typically carries a stigma, but asking for a large amount of time does not.

Lemma 6 Suppose it is appropriate to ask for help. (i) If $g_{A}^{*}$ and $g_{S}^{*}$ are both positive and monetary, then $g_{A}^{*}<g_{S}^{*}$. (ii) If $g_{A}^{*}$ and $g_{S}^{*}$ are both positive and non-monetary, then $g_{A}^{*} \geq g_{S}^{*}$.

\section{ProOF: See Appendix.}

Part (i) says that there can only be positive monetary requests by both recipient types if the selfish recipient requests more than the altruistic recipient. That is, the altruistic recipient must be signaling her type by asking for a gift that is so small that the egoistic recipient is not tempted to mimic the request. Thus, if money is given in equilibrium, large requests have to carry a stigma. Part (ii) on the other hand, suggests that there may be no stigma associated with a large non-monetary request. Here, the idea is that the altruist may have a comparative advantage when it comes to receiving time. Moreover, if an egoistic recipient were to reveal herself in equilibrium by asking for a large gift, she prefers the largest available monetary gift to the largest available time gift. 
If there is stigma associated with asking for large amounts of money and small amounts of time, it is conceivable that the egoist prefers being silent to making a request. Recall that $\eta$ is the probability that there is a valid occasion for helping. If the donor expects that the altruistic recipient will ask for help and that the selfish recipient will not, the absence of a request will thus induce the donor to think that the recipient is altruistic with probability

$$
a^{1}=\frac{a^{0}(1-\eta)}{a^{0}(1-\eta)+\left(1-a^{0}\right)} .
$$

Our next result provides a simple condition under which the egoist prefers requesting money to remaining silent.

Lemma 7 Suppose $v$ is linear. If $g_{A}^{*} \neq\{(0,0) \cup \emptyset\}$, then $g_{S}^{*}=\max \left\{\bar{g}_{S}^{m}, a^{0} \bar{g}_{A}^{m}\right\}$.

If utility is linear in money (i.e., utility is fully transferable between the donor and the recipient), the stigma from requesting money is too small to make the selfish recipient remain silent or ask for time; instead she maximizes the expected available monetary gift. The intuition is that the donor's maximum gift is determined by the esteem loss from not giving, whereas the incentive to remain silent is determined by the esteem loss from receiving. Since there is already some loss of esteem associated with being silent $\left(a^{1}<a^{0}\right)$, for a given request the receiver is less concerned with losing esteem than the donor is. Thus, with linear utility, the value of the gift exceeds the esteem loss.

While people sometimes do ask for money, we believe that it primarily happens when the recipient is considerably poorer than the donor, as in the case of begging. Our next result provides an argument for why rich recipients do not request money from poor donors, but may ask for their time.

Proposition 4 If $v$ is strictly concave and $\omega_{R} \geq \omega_{D}$, there exists an open set of parameters such that altruistic recipients request time and egoistic recipients remain silent.

Proof: See Appendix.

It almost goes without saying that egoistic recipients are more likely to remain silent when $\beta_{S}$ is relatively large; you don't ask someone to be with you if you hate to be with them. More subtly, if $v$ is concave and the donor is no richer than the recipient, the donor's loss of consumption utility is strictly greater than the recipient's gain, reducing the maximal size of the equilibrium gift. If in addition $a^{1}$ is close to $a^{0}$, as is the case when there is a small ex ante probability that help is justified, the recipient loses little esteem from remaining silent.

Although the model explains why altruists may ask for time and egoists may refrain from making requests altogether, an important objection is that monetary requests still 
occur in a seemingly wide range of circumstances. Indeed, even when the recipient is wealthier than the donor and utility is concave, the recipient may ask for money if the probability that helping is appropriate, $\eta$, is not too small.

As we shall now see, the prevalence of monetary requests is largely driven by the assumption that players do not care about each other's types. In the social preference literature, this assumption has previously been relaxed by Levine (1998), who argues that people are more altruistic towards opponents that are themselves altruistic, and by Ellingsen and Johannesson (2008), who argue that the esteem from an altruist is worth more than the esteem from an egoist. When the model is extended to take account of such conditional altruism or pride, the egoistic recipient is more prone to be silent. ${ }^{21}$

As a stark illustration, suppose people place zero weight on what egoistic opponents think about their altruism. For example, let the utility function be

$$
u_{i}=v\left(c_{i}\right)+\alpha_{i} z\left(c_{j}\right)-\beta_{i} f_{I}\left(g^{t}\right)+\frac{\alpha_{i j}}{\alpha_{A}} p\left(\hat{\alpha}_{j i}\right) .
$$

Note that, apart from the coefficient $\alpha_{i j} / \alpha_{A}$ the utility function is the same as (1).

Proposition 5 Consider the Helping Game, and let players have the utility function (11). (i) There is an open set of parameters such that altruistic recipients request time and egoistic recipients remain silent. (ii) There are no parameters such that recipients request money.

Proof: See Appendix.

Part (ii) of Proposition 5 is perhaps most remarkable, because it invokes no parameter restrictions. The reason is plain: Money is never granted in equilibrium because egoistic recipients are more tempted to ask for money than altruistic recipients are, and if the respect of an egoist is worth nothing to the donor, it is crucial for the recipient not to pose as one.

As for part (i), we merely note that the conditions are quite permissive. The requirements for the existence of an equilibrium in which only the altruists ask for help are that the concern for prestige, $p\left(\alpha_{A}\right)$, is sufficiently large, that actual altruism $\alpha_{A}$ is not too large, and that the difference in disutility of intimacy as expressed by the parameters $\left(\beta_{S}-\beta_{A}\right)$ is sufficiently large.

\footnotetext{
${ }^{21}$ Such extensions also help to explain other phenomena that have been noticed by social psychologists. For example, Jecker and Landy (1969) demonstrate that people tend to like others who have requested and gotten their help. Since altruists request help in our model, the evidence on liking would be straightforwardly explained if we would make Levine's (1998) assumption that altruism is conditional.
} 


\subsection{The compensation taboo}

In many places, there are taboos against paying cash for neighborly help; see for example Webley and Lee (1993). Likewise, we usually don't pay colleagues and friends for their assistance. The model straightforwardly explains the opposition to such payments. If the recipient makes a positive cash payment, she can ask for more help. The donor's utility is roughly the same as it would have been without the payment. The recipient, however, is worse off: Due to the inefficiencies associated with the transaction the additional help is worth less than the cash payment.

Observe that our model suggests that the compensation taboo will not apply for monetary costs; such costs can be reimbursed without inducing inefficiency. Thus, the model can explain why famous people, including leading academics, are often asked to contribute their time to various causes while being compensated only for their lodging and travel costs.

\subsection{Motivational crowding out}

Cash payments can even decrease non-monetary donations, a phenomenon that is sometimes referred to as "motivational crowding out"; see Frey and Jegen (2001) for an extensive survey and Heyman and Ariely (2004) and Mellström and Johannesson (2008) for some recent relevant evidence.

Utility functions such as (11) can contribute to explain motivational crowding out, albeit only if donations are efficient. In close analogy with the principal-agent model of Ellingsen and Johannesson (2008), the argument runs as follows: ${ }^{22}$ Suppose that donations cost less to the donor than they are worth to the recipient, and hence are efficient. Suppose furthermore that it is possible to write a partial contract specifying, for example, whether the donation is above or below a fixed level $x$. In the house move example, $x$ might specify that the donor spends a day helping out and puts in a certain minimum intensity of work effort. It is impossible to contractually specify higher levels of effort. Suppose finally that $x$ is above the separating equilibrium donation of a selfish donor, but below the separating equilibrium donation of an altruistic donor. Depending on parameters, this model has either of three solutions. If the prior belief is that the donor is highly likely to be selfish, any recipient will offer the contract. If the prior is that the donor is highly likely to be altruistic, no recipient will offer a contract. Finally, there are intermediate cases in which selfish recipients offer contracts and altruistic recipients do not. Motivational crowding out takes place in all cases, in the sense that altruistic donors are demotivated by the contract offer, and in the last case the crowding out effect is so large that the total expected donation goes down.

\footnotetext{
${ }^{22}$ For a related (but different) argument, see Bénabou and Tirole (2006).
} 


\subsection{Extensions}

The model has been kept simple in order to preserve tractability. However, a more elaborate model could answer a host of additional questions.

One extension is to consider several different tasks that the recipient can request help with. From the altruistic recipient's point of view, the ideal task is one that the donor can conduct efficiently, but where recipient participation is also considerable, so as to keep an egoistic recipient's intimacy cost high. When the donor is a friend, relatively simple activities that require some cooperation would seem ideal. This would fit the moving example when friends are fit and the move is small. ${ }^{23}$

In on-going relationships, people may ask for help on several occasions. Since altruistic donors will not provide more help than is necessary to separate from the egoists, the total amount of help is still limited. Thus, there is a trade-off between getting help immediately and waiting to get, possibly more efficient, help in the future. To the extent that feelings such as altruism change over time, signaling benefits are increased by spreading requests over time.

Another relevant extension is to consider fund raising for charities, a situation that combines features of our two games. For example, a recent field experiment by DellaVigna, List, and Malmendier (2010) finds that many potential donors opt out if they can. Specifically, if the charity distributes a flyer in advance to say when they will be coming, fewer people open the door. If the flyer allows checking a "do not disturb" box, many people do so. The authors consider the "do not disturb" behavior as evidence against the social signaling approach. We disagree. After all, it is possible that the donors are actually very busy, and have a valid excuse for not receiving solicitors. Selfish donors would then find it in their interest to ask not to be disturbed rather than opening the door and give nothing or trifles (embarrassingly small positive donations do not occur in our two-type model, but are a feature of more realistic models with a continuum of types). ${ }^{24}$

Likewise, by extending the Celebration Game to admit a subsequent action by the recipient and applying the utility function (11), we have a gift exchange model. The difference from the model in Ellingsen and Johannesson (2008), is that there the principal's action consisted of a contract choice. The gift exchange model might potentially explain workers' reciprocity in the field experiment of Kube, Maréchal, and Puppe (2010) that we described in Section 3.4.

\footnotetext{
${ }^{23}$ For a large household, a few altruistic friends don't suffice to carry out all the lifting and packaging, and professional movers would have to do part of the job. Once involved, these movers have a considerable efficiency advantage.

${ }^{24}$ An additional benefit of checking the "do not disturb" box is that it is more anonymous than opening the door; it is more difficult for the solicitor to identify the which person in the household is losing esteem. Moreover feelings of pride and shame are probably accentuated by personal contact. (There is no such proximity parameter in the model now, but the extension is plain.)
} 
Finally, several of the extensions that we considered for the Celebration Game (Section 4.3) are relevant to the Helping Game as well. For example, we could allow the donor to have valid excuses for not helping, which would reduce the amount of help the recipient can ask in equilibrium. We could also consider the negotiation of helping norms in society.

\section{Final remarks}

We have investigated the old idea that generous behavior is often a matter of symbolic social exchange. The gift is a signal, and the payment is esteem. Building on the previous formal models Camerer (1988) and Prendergast and Stole (2001), we first provided a relatively general characterization of the circumstances under which donors prefer giving inefficient non-monetary gifts. With these insights in hand, we proceeded to ask the new question: When will recipients request inefficient non-monetary gifts?

The model suggests that egoists prefer to refrain from making requests rather than (i) revealing their egoism through a request for money or (ii) pretending to enjoy the social interaction that a non-monetary gift entails. Requests of non-monetary gifts, such as neighborly help, are thus credible signals of altruism or liking rather than signs of greed.

Along the way, we have identified some directions for further work, but there are many others. For example, we might consider a wider range of gifts and a wider range of motivations. Can signaling concerns help to understand why people donate blood and organs? And is it possible that helpful people are concerned with signaling other traits than their altruism? In our view, the latter question is particularly promising. Specifically, we conjecture that people are often willing to offer their help in return for admiration of their skills. ${ }^{25}$

Another natural question concerns the implications of our findings for fundraising. Fundraisers essentially ask for help on the behalf of others. Thus, their requests do not reveal information about fundraisers themselves. It thus follows from the logic of Observation 4, that the fundraiser will ask for money. We think that a suitably adapted version of this model can be used for deriving optimal explicit requests and comparing these to open-ended solicitation. That extended model could potentially also shed light on the evidence from a recent field experiment by DellaVigna, List, and Malmendier (2010), who allow potential donors to avoid solicitation by checking a Do Not Disturb box on the solicitation flyer. The study indicates that many people who avail themselves of the option to check the box would have paid a small amount if they had been confronted with the fundraiser.

\footnotetext{
${ }^{25}$ For example, we think that academics invest effort into writing anonymous referee reports in return for little or no pay at least partly because they want to make a favorable impression on the journal editor, especially if the editor is someone that the academic referees themselves respect.
} 


\section{References}

Andreoni, J. (1989). Giving with impure altruism: Applications to charity and Ricardian equivalence, Journal of Political Economy 97, 1447-1458.

Andreoni, J. (2006). Philantropy, Chapter 18 of S.-C. Kolm and J.M. Ythier (eds.), Handbook of the Economics of Giving, Altruism and Reciprocity, Amsterdam: Elsevier.

Andreoni, J. And Bernheim, B.D. (2009). Social image and the 50:50 norm: A theoretical and experimental analysis of audience effects, Econometrica 77, 16071636.

Andreoni, J. And Petrie, R. (2004). Public goods experiments without confidentiality: A glimpse into fund-raising. Journal of Public Economics 88, 1605-1623.

Ariely, D., Bracha, A. And Meier, S. (2009). Doing good or doing well? Image motivation and monetary incentives in behaving prosocially. American Economic Review 99, 544-555.

Aronson, E. (2004) The Social Animal. 9th Edition. New York: Worth Publishers.

Becker, G. (1974): A theory of social interactions, Journal of Political Economy 82, 1063-1093.

BÉnabou, R. and Tirole, J. (2006). Incentives and prosocial behavior. American Economic Review 96, 1652-1678.

Blackorby, C. And Donaldson, D. (1988). Cash versus kind, self selection, and efficient transfers. American Economic Review 78, 691-700.

Bliege Bird, R. And Smith, E.A. (2005). Signaling theory, strategic interaction, and symbolic capital. Current Anthropology 46, 221-248.

Bourdieu, P (1977). Outline of a Theory of Practice. Cambridge: Cambridge University Press.

Bourdieu, P (1984). Distinction: A Social Critique of the Judgement of Taste. Cambridge: Harvard University Press.

Brennan, G. And P. Pettit (2004): The Economy of Esteem. Oxford: Oxford University Press.

Broberg, T., Ellingsen, T. And Johannesson, M. (2007). Is generosity involuntary? Economics Letters 94, 32-37. 
Bruce, N. and Waldman, M. (1991). Transfers in kind: Why they can be efficient and nonpaternalistic. American Economic Review 81, 1345-1351.

Camerer, C.F. (1988): Gifts as economic signals and social symbols. American Journal of Sociology 94 (Supplement), S180-S214.

Carmichael, H.L. And MacLeod, W.B. (1997). Gift giving and the evolution of cooperation. International Economic Review 38, 485-509.

Carrier, J.G. (1995). Gifts and Commodities. London: Routledge.

Cho, I.-K. And Kreps, D.M. (1987): Signaling games and stable equilibria. Quarterly Journal of Economics 50, 179-221.

Coleman, J.S. (1990). Foundations of Social Theory. Cambridge: The Belknap Press of Harvard University Press.

Dana, J., Cain, D.M., And Dawes, R. M. (2006). What you don't know won't hurt me: Costly but quiet exit in dictator games. Organizational Behavior and Human Decision Processes 100, 193-201.

Della Vigna, S., List, J., And Malmendier, U. (2010). Testing for altruism and social pressure in charitable giving. N.B.E.R. Working Paper 15629.

Denrell, J. (1998): Incentives and hypocrisy. Chapter 2 in the $\mathrm{PhD}$ dissertation Essays on the Economics of Vanity and Career Concerns. Stockholm: Stockholm School of Economics.

DeVoe, S.E. And Iyengar, S.S. (2010). Medium of exchange matters: What's fair for goods is unfair for money, Psychological Science, forthcoming.

Ellingsen T. And Johannesson, M. (2007). Paying respect. Journal of Economic Perspectives 21 (Fall): 135-149.

Ellingsen T. And Johannesson, M. (2008). Pride and prejudice: The human side of incentive theory. American Economic Review 98, 990-1008.

Ellingsen T. And Johannesson, M. (2009). Time is not money. Journal of Economic Behavior and Organization 72, 96-102.

Elster J. (1983). Sour Grapes. Cambridge: Cambridge University Press.

Frey, B.S. And Jegen, R. (2001): Motivation crowding theory, Journal of Economic Surveys 15, 589-611. 
Glazer, A. And Konrad, K.A. (1996). A signaling explanation for charity. American Economic Review 86, 1019-1028.

Harbaugh, W. (1998a): The prestige model for making charitable transfers. American Economic Review Papers and Proceedings 88, 277-282.

Harbaugh, W. (1998b): What do donations buy? A model of philanthropy based on prestige and warm glow, Journal of Public Economics 67, 269-284.

Heyman,J. And Ariely, D. (2004). Effort for payment: A tale of two markets, Psychological Science 15, 787-793.

HobBes, T. (1651). Leviathan. London: Andrew Crooke.

Homans, G. (1961). Social Behaviour: Its Elementary Forms. London: Routledge.

Hume, David. 1739. A Treatise of Human Nature, London: John Noon.

JECKER, J. AND LANDY, D. (1969). Liking a person as a function of doing him a favor. Human Relations 22, 371-378.

KAYA, A. (2009). Repeated signaling games, Games and Economic Behavior 66, 841854.

Kube, S., Maréchal, M.A., And Puppe, C. (2010). The currency of reciprocity — Gift exchange in the workplace. IEW Working paper 377, University of Zurich.

Landry, C.E., Lange, A., List, J.A., Price, M.K., And Rupp, N.G. (2006). Toward an understanding of the economics of charity: Evidence from a field experiment. Quarterly Journal of Economics 121, 747-782.

Lazear, E., Malmendier, U., And Weber, R. (2010). Sorting, prices, and social preferences. Manuscript, University of California, Berkeley.

Lee, L.C., Piliavin, J.A., And Call, V.R.A. (1999). Giving time, money, and blood: Similarities and differences. Social Psychology Quarterly 62, 276-290.

Levine, D. K. 1998. Modeling altruism and spitefulness in experiments. Review of Economic Dynamics 1, 593-622.

List, J.A. And Shogren, J.F. (1998): The deadweight loss of Christmas: comment. American Economic Review 88, 1350-1355.

Mailath, G., Okuno-Fujiwara, M. and Postlewaite, A. (1993). On belief based refinements in signaling games. Journal of Economic Theory 60, 241-276. 
Mauss, M. (1925). The gift: The form and reason for exchange in archaic societies. (Original: Essai sur le Don.) English translation W.D. Halls, 1990. London: Routledge.

Mellström, C. And Johannesson, M. (2008). Crowding out in blood donation: Was Titmuss right? Journal of the European Economic Association 6, 845-863.

Myerson, R.B. (1985). Analysis of two bargaining problems with incomplete information, in A.E. Roth (ed.): Game Theoretic Models of Bargaining, Cambridge: Cambridge University Press.

Nelson, P.J. and Greene, K.V. (2003). Signaling Goodness: Social Rules and Public Choice, Ann Arbor: University of Michigan Press.

Offer, A. (1997). Between the gift and the market: The economy of regard. Economic History Review 50, 450-476.

Pfeffer, J. And DeVoe, S.E. (2008). Economic evaluation: The effect of money and economics on attitudes about volunteering, Journal of Economic Psychology 30, 500-508.

Plott, C.R. And K. Zeiler (2007): Exchange asymmetries incorrectly interpreted as evidence of endowment effect theory and prospect theory, American Economic Review 97, 1449-1466.

Pollak, R.A. (1988). Tied transfers and paternalistic preferences. American Economic Review Papers and Proceedings 78, 240-244.

Prendergast, C. and Stole, L. (2001). The Non-monetary nature of gifts. European Economic Review 45, 1793-1810.

RABin, M. (2000). Risk aversion and expected utility: A calibration theorem, Econometrica 68, 1281-1292.

Robben, H.S.J And Verhallen, T.M.M. (1994). Behavioral costs as determinants of cost perception and preference formation for gifts to give and gifts to receive. Journal of Economic Psychology 15, 333-350.

SATOw, K. (1975). Social approval and helping. Journal of Experimental Social Psychology 11, 501-509.

Schwartz, B. (1967). The social psychology of the gift. American Journal of Sociology $73,1-11$.

Smith, A. (1790). The Theory of Moral Sentiments. 6th edition (First edition 1759). London: A. Millar. 
Soetevent, A. R. (2005). Anonymity in giving in a natural context - A field experiment in 30 churches. Journal of Public Economics 89, 2301-2323.

Solnick, S. And Hemenway, D. (1996): The deadweight loss of Christmas: comment. American Economic Review 86, 1299-1305.

Veblen, T. (1934). The Theory of the Leisure Class. New York: Modern Library.

Titmuss, R. (1971). The Gift Relationship: From Human Blood to Social Policy. London: George Allen and Unwin.

Vohs, K.D., Mead, N.L. And Goode, M.R. (2006). The psychological consequences of money, Science 314, 1154-1156.

Waldfogel, J. (1993). The deadweight loss of Christmas. American Economic Review 83, 1328-1336.

Waldfogel, J. (1998). The deadweight loss of Christmas: reply. American Economic Review 88, 1358-1359.

WAldFogel, J. (2002). Gifts, cash, and stigma, Economic Inquiry 40, 415-427.

Webley, P. And LeA, S.E.G. (1993). The partial unacceptability of money in repayment for neighborly help. Human Relations 46, 65-76.

Wright, R. (1994). The Moral Animal. London: Brown and Company.

Zahavi, A. (1995). Altruism as handicap - the limitations of kin selection and reciprocity. Journal of Avian Biology 26, 1-3.

Zelitzer, V.A.R. (1994). The Social Meaning of Money. New Jersey: Princeton University Press. 


\section{Appendix}

\subsection{Proof of Lemma 1}

(i) Establishing equilibrium. Let us first propose the following set of out-of-equilibrium beliefs which sustain the outcome as a PBE: The recipient believes that any gift $g^{m}<$ $\check{g}^{m}$ comes from an egoist.

With these beliefs, a selfish donor is strictly worse off following any deviation $g^{m} \in$ $\left(0, \check{g}^{m}\right)$, since the esteem remains at $P\left(\hat{\alpha}_{S}\right)$. By construction the deviation $\check{g}^{m}$ yields the same utility as $g^{m}=0$. Moreover, any deviation to $g^{m}>\check{g}^{m}$ cannot increase esteem above the maximum level $P\left(\hat{\alpha}_{A}\right)$ that is attained already with the gift $\check{g}^{m}$, and by (2) we know that any increase in giving will have a negative direct effect on the donor's utility. Thus, the proposed strategy for the selfish donor constitutes a best reply.

Likewise, the altruistic donor has nothing to gain by choosing $g^{m} \neq \check{g}^{m}$; any smaller gift reduces the pride to zero (which leads to a utility no greater than the egoist's equilibrium utility, which is smaller than the altruist's equilibrium utility), whereas any larger gift cannot increase pride, and has a negative direct effect on utility because of (2) and the concavity of $v$ and $z$.

(ii) Uniqueness. There are many other outcomes satisfying the PBE criterion. For example, there is an equilibrium in which neither type of donor gives any gift, and the recipient's esteem for the donor is $\hat{\alpha}=a^{0} \alpha_{A}+\left(1-a^{0}\right) \alpha_{S}=a^{0} \alpha_{A}$. This outcome can be sustained, inter alia, by the recipient belief that any positive gift comes from a selfish donor. However, such out-of-equilibrium beliefs fail the Intuitive Criterion, because there exist positive gifts that reduce the utility of a selfish donor regardless of the recipient's belief, but increases the utility of an altruistic donor for some beliefs. To be specific, these are gifts just above $\tilde{g}^{m}$ that is (uniquely) defined by the equality

$$
v\left(\omega_{D}+\bar{t}\right)+\alpha_{S} z\left(\omega_{R}+\bar{t}\right)+p\left(a^{0} \alpha_{A}\right)=v\left(\omega_{D}+\bar{t}-g^{m}\right)+\alpha_{S} z\left(\omega_{R}+\bar{t}+g^{m}\right)+p\left(\alpha_{A}\right) .
$$

Using analogous arguments, it is straightforward to demonstrate that all other pooling and semi-separating equilibria also fail the Intuitive Criterion.

\subsection{Proof of Lemma 3}

Suppose that $\pi^{m}>\pi^{t}$. The question is whether the availability of time gifts destroys the preferred money gift equilibrium. The answer is negative for the following reason: The equilibrium could only fail the Intuitive Criterion if there were a time gift $g^{t}$ with the properties that (i) $g^{t}$ yields a higher reward to the altruist and (ii) $g^{t}$ does not yield a higher reward to the egoist. But if such a time gift existed, then it would have induced a separating equilibrium in the restricted game with time gifts only, contradicting the assumption that $\pi^{m}>\pi^{t}$. Suppose instead that $\pi^{t}>\pi^{m}$. Then, the money gift equilibrium does not satisfy the Intuitive Criterion, because the altruistic 
donor can defect and give time $g_{S}^{t}+\epsilon$, where $\epsilon$ is a small positive amount. This defection can never be rational for an egoist, so the recipient should infer that the gift is given by an altruist, whence the defection pays off.

\subsection{Proof of Proposition 1}

Differentiate with respect to $\gamma$ in equation (7). From (5) we see that $g_{S}^{m}$ is independent of $\gamma$, whereas from (6) we see that $\check{g}^{t}$ is independent of $\gamma$. Hence, the derivative is $\alpha_{A} z^{\prime}\left(\omega_{R}+\bar{t}+\gamma \check{g}^{t}\right) \check{g}^{t}>0$.

\subsection{Proof of Proposition 2}

Since gifts are bounded above by the (monetary equivalent of the) value of esteem, and $\lim _{\omega_{R} \rightarrow \infty} z^{\prime}\left(\omega_{R}+\bar{t}\right)=0$, the difference $z\left(\omega_{R}+\bar{t}+\gamma \check{g}^{t}\right)-z\left(\omega_{R}+\bar{t}+\check{g}^{m}\right)$ goes to zero as $w_{R}$ goes to infinity. Since $\check{g}^{t}$ remains well above 0 (by inspection of equation (6)) even in this limit, it follows from (7) that $\Delta>0$ in the limit. By continuity, $\Delta$ is also positive for all levels of recipient wealth above some finitely large $\omega_{R}$.

\subsection{Proof of Lemma 4}

Note that complying with the request and obtaining esteem $a^{0} \alpha_{A}$ is a best reply if the recipient holds the (out-of-equilibrium) belief that a refusal reveals the donor to be selfish, and this belief obviously satisfies D1. It remains to check that refusing the request violates D1. Step (i): Note that there are no separating equilibria following such a modest request. Step (ii): The pooling equilibrium in which both types refuse the request fails D1 for the following reason: If both types refuse to comply with a tiny request, it must be because the recipient holds more pessimistic beliefs about the donor's type in case the donor grants than if the donor refuses. However, since there is a larger set of recipient out-of-equilibrium beliefs that justify a small upward deviation by the altruistic donor than by the selfish donor, the supposed pessimistic beliefs violate D1.

\subsection{Proof of Lemma 6}

The proof is by contradiction. Part (i). Suppose first to the contrary that the altruist asks for strictly more money than the egoist. Then the egoist gains both money and esteem by mimicking the altruist - a contradiction. Suppose next that both types ask for the same positive amount. Then, the set of donor beliefs that would make it profitable for an altruistic recipient to ask for a slightly smaller amount is a superset of the corresponding selfish recipient beliefs. Thus, under D1 a small reduction in request would be associated with a large increase in esteem, making the defection profitable. 
Part (ii) Suppose first to the contrary that the altruist asks for strictly less time than the egoist. Then, the egoistic recipient is revealed in equilibrium. However, regardless of donor beliefs it is then strictly better for the recipient to ask for money (because $\bar{g}_{i}^{m}>\gamma \bar{g}_{i}^{t}$ ). Suppose next that the altruist and the egoist ask for the same amount of time. Then, the set of donor beliefs that would make it profitable for an altruistic recipient to ask for a slightly smaller amount of time is a superset of the corresponding selfish recipient beliefs. Thus, under D1 a small reduction in request would be associated with a large increase in esteem, again contradicting the supposition that they may ask for the same amount of time in equilibrium.

\subsection{Proof of Lemma 7}

Consider first the case $a^{0} \bar{g}_{A}^{m}<\bar{g}_{S}^{m}$. Then, if requesting money the egoistic recipient will ask for $\bar{g}_{S}^{m}$. If the functions $v$ and $p$ are linear (with slopes $v^{\prime}$ and $p^{\prime}$ ), we see from (8) that $\bar{g}_{S}^{m}$ is the solution to $v^{\prime} \bar{g}_{S}^{m}=p^{\prime} a^{0} \alpha_{A}$. In general, a selfish recipient only remains silent if $v\left(\omega_{R}+\bar{t}+\bar{g}_{S}^{m}\right) \leq v\left(\omega_{R}+\bar{t}\right)+p\left(a^{1} \alpha_{A}\right)$. In the linear case, the condition becomes $v^{\prime} \bar{g}_{S}^{m} \leq p a^{1} \alpha_{A}$. Inserting $\bar{g}_{S}^{m}$, we see that the latter condition requires $a^{1} \geq a^{0}$, a contradiction. An analogous argument applies in the case $a^{0} \bar{g}_{A}^{m}>\bar{g}_{S}^{m}$.

\subsection{Proof of Proposition 4}

The parameter region of interest has the following properties: (i) $\eta$ and $\gamma$ are small; (ii) $\beta_{S}-\beta_{A}$ is large compared to $\alpha_{A}$, (iii) $p\left(\alpha_{A}\right)$ is large. For simplicity, we also make the assumption $a^{0} \bar{g}_{A}^{m}<\bar{g}_{S}^{m}$.

Let us initially confine our attention to the case in which only time gifts can be asked, and then check that this restriction is not binding. We first prove that there are parameters such that the proposed behavior forms a PBE. Suppose the altruist makes the request $\hat{g}^{t}$ such that the selfish recipient is indifferent between remaining silent and mimicking:

$$
v\left(\omega_{R}+\bar{t}\right)+p\left(a^{1} \alpha_{A}\right) \geq v\left(\omega_{R}+\bar{t}+\gamma \hat{q}^{t}\right)-\beta_{S} f_{R}\left(\hat{q}^{t}\right)+p\left(\alpha_{A}\right) .
$$

An altruistic recipient prefers to make the request if

$$
\begin{aligned}
v\left(\omega_{R}+\bar{t}\right)+p\left(a^{1} \alpha_{A}\right)< & v\left(\omega_{R}+\bar{t}+\gamma \hat{q}^{t}\right)-\beta_{A} f_{R}\left(\hat{q}^{t}\right) \\
& -\alpha_{A}\left[z\left(\omega_{D}+\bar{t}\right)-z\left(\omega_{D}+\bar{t}-\hat{q}^{t}\right)\right]+p\left(\alpha_{A}\right) .
\end{aligned}
$$

The right-hand side of (13) is larger than the right-hand side of (12) if

$$
\left(\beta_{S}-\beta_{A}\right) f_{R}\left(\hat{q}^{t}\right)>\alpha_{A}\left[z\left(\omega_{D}+\bar{t}\right)-z\left(\omega_{D}+\bar{t}-\hat{q}^{t}\right)\right]
$$

so (13) is satisfied whenever $\beta_{S}-\beta_{A}$ is sufficiently large compared to $\alpha_{A}$. 
Recall that $\bar{g}_{S}^{t}$ is the maximum time gift that a selfish donor is willing to grant. Thus, the proposed solution is feasible if $\hat{g}^{t} \leq \bar{g}_{S}^{t}$. To satisfy feasibility, choose parameters such that $\hat{g}^{t}$ is small: let $a^{1}$ be close to $a^{0}$ (by lowering $\eta$ ) and let $\gamma$ be small.

We next provide a condition under which the outcome uniquely satisfies D1, namely

$$
\gamma v^{\prime}\left(\omega_{R}+\bar{t}+\gamma \hat{q}^{t}\right)<\beta_{A} f_{R}^{\prime}\left(\hat{q}^{t}\right)+\alpha_{A} z^{\prime}\left(\omega_{D}+\bar{t}-\hat{q}^{t}\right)
$$

The condition implies that, for a given level of prestige, an altruistic recipient does not want to increase the request beyond $\hat{q}_{S}^{t}$.

Let us now admit monetary gifts. Suppose $a^{0}$ satisfies $a^{0} \bar{g}_{A}^{m}<\bar{g}_{S}^{m}$. We have already ruled out the possibility that selfish recipients will ask strictly less than $\bar{g}_{S}^{m}$ in this case. Consider first the possibility that both recipient types pool at the request $\bar{q}_{S}^{m}$. Since the set of donor responses that would justify this deviation is greater for the selfish recipient than for the altruistic recipient, under D1 this deviation is inferior for the altruistic recipient if

$$
\begin{aligned}
v\left(\omega_{R}+\bar{t}+\bar{g}_{S}^{m}\right)< & v\left(\omega_{R}+\bar{t}+\gamma \hat{q}^{t}\right)-\beta_{A} f_{R}\left(\hat{q}^{t}\right) \\
& -\alpha_{A}\left[z\left(\omega_{D}+\bar{t}-\bar{g}_{S}^{m}\right)-z\left(\omega_{D}+\bar{t}-\bar{q}_{S}^{t}\right)\right]+p\left(\alpha_{A}\right) .
\end{aligned}
$$

Trivially, the inequality is satisfied if $p\left(\alpha_{A}\right)$ is sufficiently large.

Consider next the possibility that only the egoistic recipient requests the monetary gift $\bar{g}_{S}^{m}$. Recall that $\bar{g}_{S}^{m}$ is given by the equation

$$
v\left(\omega_{D}+\bar{t}\right)-v\left(\omega_{D}-\bar{t}-\bar{g}_{S}^{m}\right)=p\left(a^{0} \alpha_{A}\right) .
$$

Remaining silent is better than asking for money if

$$
v\left(\omega_{R}+\bar{t}+\bar{g}_{S}^{m}\right)-v\left(\omega_{R}-\bar{t}\right)<p\left(a^{1} \alpha_{A}\right) .
$$

Because $\alpha^{1}<\alpha^{0}$ the right hand side of the equality is greater than the right hand side of the equality. However, when $v$ is strictly concave and $\omega_{D}<\omega_{R}$, the left hand side of the inequality is smaller than the left hand side of the equality. Thus, if $\eta$ is sufficiently small (so that $a^{1}$ is sufficiently close to $a^{0}$ ), the inequality is satisfied.

\subsection{Proof of Proposition 5}

Part (i): Since this part is almost identical to the proof of Proposition 4, a sketch suffices. Start by characterizing the equilibrium that would obtain if only time gifts are under consideration, deriving the conditions for separation and feasibility. Then allow monetary gifts, and show that deviation to monetary requests do not destabilize the proposed equilibrium. Part (ii): Since no donor is willing to give a gift unless it is a source of prestige, and since no prestige is associated with the beliefs of an egoistic recipient, monetary requests will never be granted to egoists in a separating 
equilibrium. However, no pooling equilibrium with monetary gifts exists either: There is always a set of donor responses that justify a downward deviation in request by the altruistic recipient, and since this set is a superset of the donor responses that justify such a deviation for the egoistic recipient, such a pooling equilibrium fails D1. 